OPEN ACCESS

Edited by: Yin Ma,

Lanzhou University, China

Reviewed by:

Chih-Chun Kung,

Jiangxi University of Finance and

Economics, China

Zhaohui Liu,

West Yunnan University of Applied

Sciences, China

*Correspondence:

Haiyan Song

songhaiyan2021@sohu.com

Tanaporn Hongsuchon

tanaporn.h@chula.ac.th

Specialty section:

This article was submitted to Organizational Psychology,

a section of the journal

Frontiers in Psychology

Received: 12 November 2021 Accepted: 08 December 2021 Published: 12 January 2022

Citation:

Song $H$, Hongsuchon $T$, Kittikowit S and Dong Z (2022) Assessing the Antecedents and

Consequence of Enterprise

Transformation: A Quantitative

Approach.

Front. Psychol. 12:813858. doi: 10.3389/fpsyg.2021.813858

\section{Assessing the Antecedents and Consequence of Enterprise Transformation: A Quantitative Approach}

\author{
Haiyan Song ${ }^{1 *}$, Tanaporn Hongsuchon ${ }^{2 *}$, Santhaya Kittikowit ${ }^{2}$ and Zhe Dong ${ }^{1}$ \\ 'Trade and Economic Management School, Huzhou Vocational and Technical College, Huzhou, China, ${ }^{2}$ Chulalongkorn \\ Business School, Chulalongkorn University, Bangkok, Thailand
}

With the negative impact of COVID-19, the continuous recession of economic globalization, and the increasing market competition, enterprise transformation gradually becomes the theme of enterprise management. Although more and more scholars and companies have paid attention to the importance of enterprise transformation, most of the research on it is still at the qualitative level of theoretical descriptions and lacks a comprehensive consideration and empirical research on its motivation and performance. In view of this, this study analyzes the overall driving effect of technological innovation and the internal and external environment on enterprise transformation from the perspective of its drivers and analyzes in depth its causes and consequences for different industries (construction and real estate industries). The study also analyzes the antecedents and consequences of enterprise transformation and its differences in different industries (construction and real estate). In this study, a sample of middle and senior management of 10 companies with a valid sample of 401 is collected. Structural equation modeling results indicate that competitive advantage, technological innovation, and market pressure significantly affect enterprise transformation, which is an antecedent of corporate performance. Further, the results of the multiple-group analysis also reveal some significant differences between the theoretical models of the construction and real estate communities. Finally, suggestions are made based on the findings.

Keywords: technological innovation, enterprise transformation, corporate performance, market pressure, multiple-group analysis

\section{INTRODUCTION}

In recent years, scholars have proposed many research themes and frontier hotspots in the field of enterprise transformation research, including transformation motives (Yang et al., 2017; Zhao et al., 2020; Vrolijk, 2021), global value chain (Gereffi and Lee, 2016; Song et al., 2016; Reis et al., 2021), transformation strategies and paths (Zhu, 2019; Efogo, 2020; Yang et al., 2021), transformation models (Schaltegger et al., 2016; Li et al., 2019; Cao, 2020), transformation experiences and case studies (Mao and Wen, 2012; Zhou et al., 2018; Jia et al., 2021). Obviously, as a competitive strategy to enhance the competitiveness or high 
value-added of enterprises, enterprise transformation has become a hot topic of attention in academic and practical circles and has become a meaningful and rich topic of discussion and management research in the field of businessmarket relationship. In the context of COVID-19 and China's economic transformation, it has become the mainstream of business management for companies to respond positively to the transformation (Yuan et al., 2020; Fu et al., 2021; Kong et al., 2021). Therefore, enterprise transformation has become increasingly important in market competition and relying on transformation to maintain continuous change and innovation capabilities extremely important for companies to survive and thrive in a rapidly changing business environment. The existing literature analyzes the importance of enterprise transformation theory from the following aspects.

First, enterprise transformation helps to alleviate the pressure of upgrading. The timely choice of transformation by firms helps firms avoid the pressure that the original industry has become difficult to provide sufficient growth space for firms (Crossa, 2021), helps improve the competitive position of firms within the industry, influences firms to enter industries with profitability (Leao and da Silva, 2021), helps firms to enter more profitable capital and technology-intensive fields (Poon, 2004), influences firms to move from low value-added activities to high value-added activities (Kong et al., 2021), and influences firms to move from simple activities to complex design and $\mathrm{R} \& \mathrm{D}$ innovation, thus improving competitiveness and business performance (Jia et al., 2021).

Second, enterprise transformation helps to enhance core competitiveness (Bell and Albu, 1999). Enterprise transformation propels enterprises to transform from OEM to ODM, or even advanced forms such as DMS and EMS, to enhance technological competitiveness; it propels enterprises to transform from OEM and ODM to OBM, to enhance brand competitiveness; or it propels enterprises to exploit technological synergies, thus entering industries with greater value-added potential (Zhu et al., 2006). By moving from contract manufacturing (OEM) to R\&D and design (ODM) and establishing independent brands (OBM), improving product quality and enhancing international competitiveness (Mao et al., 2010), and ultimately achieving independent innovation and transformation of enterprises (Amsden, 1989; Zhao et al., 2020).

Third, enterprises transformation helps increase value-added. Enterprises actively engage in transformation activities can make enterprises restructure production factors, influence the improvement of input-output efficiency, and realize process upgrading; drive enterprises to introduce advanced production lines, influence the improvement of existing products and the launch of new products, and realize product upgrading; enable enterprises to increase the added value of products, influence the trade-off of existing functions and the acquisition of new functions, and realize function upgrading; then promote the transfer of industrial knowledge, which acts on related industries, and then realizes industrial upgrading (Gereffi and Lee, 2016). Therefore, for enterprises, "realizing independent innovation and transformation path" can not only "explore new business and development directions," but also "obtain and maintain a stable competitive advantage" through the increase of added value in the industrial chain (Humphrey and Schmitz, 2002; Kaplinsky and Morris, 2003; Kong et al., 2021).

Thus, although the importance of enterprise transformation has been recognized by many enterprises and academics, and a series of valuable results have been obtained from related researches, the existing literature on the drivers of enterprise transformation still has several shortcomings in the following aspects. The existing literature focuses on the driving effect of independent variables on enterprise transformation, but there is no research on the driving mechanism of technological innovation under the combined effect of internal and external conditions. Enterprise transformation is influenced by the external environment, especially the competitive market pressure faced by technological innovation, and is also constrained by the competitive advantage in the internal environment. A comprehensive analysis of technological innovation and its internal and external influencing factors is beneficial for a deeper understanding of the driving effect of enterprise transformation. Studies have considered technological innovation as an important antecedent driver of enterprise transformation, ignoring the evaluation of the acquisition of sustainable competitiveness and the improvement of the added value of products and services, that is, the evaluation of the corporate performance of enterprise transformation. In addition, research has neglected the evaluation of the acquisition of sustainable competitiveness and the improvement of added value of products and services, that is, the measurement of corporate performance as a result of enterprise transformation. The existing studies mainly focus on samples from developed countries, and there is a lack of research on the construction of the theoretical system of enterprise transformation in China.

Based on the above discussion, this study takes COVID-19 as the research background, constructs a theoretical model of internal and external conditions affecting enterprise transformation, takes local real estate enterprises as the research object, and takes middle and senior managers of enterprises as effective samples, uses structural equation modeling to verify the explanatory power of the mechanism of action of enterprise transformation and upgrading, analyzes how technological innovation has a driving effect on enterprise transformation and upgrading under the overall market pressure and competitive advantage, so as to understand the important influencing factors affecting enterprise transformation and upgrading and their antecedents and consequences. This study provides practical guidance on the role mechanism of enterprise transformation under COVID-19 and theoretical support for improving the mechanism of enterprise transformation by deeply exploring its inherent theoretical logic and influence mechanism.

\section{LITERATURE REVIEW AND RESEARCH HYPOTHESES}

\section{The Driving Role of Technological Innovation}

As an important driver of enterprise transformation, technological innovation is conducive to the continuous improvement of product or service quality, which helps enterprises to meet 
the consumer's consumption intention and demand well, thus enhancing the market share and enterprise market competitiveness. In addition, technological innovation contributes to the renewal of production processes and procedures, the improvement of production efficiency and the reduction of production costs, and ultimately the improvement of business performance (Hame, 1998; Cohen, 2010). Corporate performance is an important evaluation indicator of business operation and development. Its financial indicators can reflect the productive capacity of the company, the synergistic effect of the division of labor and cooperation among the team members of the company, and the trust and sense of belonging of the employees to the development of the company (Hackman, 1987).

It has been shown that technological innovation can enhance corporate performance (Jefferson et al., 2006). Xu et al. (2018) took equipment manufacturing enterprises as the research object and argued that corporate technological innovation had a significant positive impact on corporate performance from the perspective of low-carbon theory through a combination of qualitative and quantitative methods. Based on the theory of disruptive innovation, Wu et al. (2013) showed through an empirical test of 201 firms' data that technological innovation not only had a significant impact on corporate performance, but also found that the relationship between different combinations of technological innovation and market orientation have distinct effects on corporate performance.

Based on this, we propose the following hypothesis.

\section{H1: Technological innovation is positively related to} corporate performance.

Technological innovation has a driving role in enterprise transformation. To meet the continuous challenges of transformation, companies are required to improve their existing products, technologies, and market services through technological innovation in order to optimize their organizational structure, reduce production costs and increase operational efficiency (Zhang and Zhao, 2015). By relying on new technology development, new business development, optimization of business operation model and internal organizational restructuring, and even equipment renewal, enterprise transformation enters into higher value-added industries, which drives the improvement of production processes, manufacturing methods, and product quality, thus promoting enterprises from the lower end of the value chain to the higher end of the value chain and ultimately improve their competitiveness. Enterprise transformation can increase the share of revenue from new types of business, improve product quality and brand image, and increase the added value of products. Thus, technological innovation helps to drive transformation by changing the technological trajectory of the firm (Lin et al., 2015).

The high correlation that exists between technological innovation and transformation has been argued by prior studies. For example, in studying the factors influencing enterprise transformation in manufacturing industries of China, Kong (2012) examined the link between enterprise innovation behavior and enterprise size and enterprise transformation through statistical empirical evidence, and based on this, he used a binary choice model to find that enterprise innovation capability is the most critical factor of enterprise transformation. Bi et al. (2017) found that low-carbon technological innovation had a significant driving effect on manufacturing industry upgrading when they investigated the relationship between manufacturing industry upgrading and low-carbon technological breakthrough innovation. Based on the above discussion, we propose the following hypothesis.

H2: Technological innovation is positively related to enterprise transformation.

Technological innovation enables a company to provide more attractive products or services than its competitors, and to gain a sustainable competitive advantage in a highly competitive industry. Compared with competitors, technological innovation enables companies to gain economies of scale and learning curve effects in the market competition, which helps companies to provide products or services that are acceptable to customers at the lowest production cost and keep the cost of products or services at the leading level in the industry. Equally important, technological innovation is used by firms to provide unique products or services to customers in certain segments of the value chain and win their favor. As an important source of low-cost competitive advantage or differentiated competitive advantage, technological innovation has a great impact on the competitive advantage of a company.

It has been shown that technological innovation has a significant role in determining the relative cost position or differentiation of products. Mang (1998) pointed out that by investing more in $\mathrm{R} \& \mathrm{D}$ and implementing product differentiation strategies, one can win a dominant position in a competitive market and gain competitive advantage. Wang (2007) concluded through an empirical study that indigenous technological innovation is a significant influencing factor to improve the competitive advantage of manufacturing trade, and further drive technological innovation. Thus, this study suggests that there is a significant linkage between technological innovation and competitive advantage. Based on this, we propose the following hypothesis.

\section{H3: Technological innovation is positively related to competitive advantage.}

\section{The Mechanism of Enterprise Transformation on Corporate Performance}

Enterprise transformation helps enterprises to enhance their competitive advantage and obtain great economic benefits. Through transformation, enterprises can participate in social division of labor in the capital and technology-intensive economy at the higher end of the value chain (Gereffi, 1999), enhance their competitive advantage and produce value-added products with technological and market advantages (Humphrey and Schmitz, 2004), and shift from the role of producers of labor-intensive low-value products to manufacturers of capital- or 
technology-intensive products (Poon, 2004), thus gaining competitive advantage and high returns. At the same time, in order to cope with the crisis caused by the change of business environment or the challenge caused by the renewal of the industry in which the company is located (Porter, 1991), it is also a strategic motive for companies to obtain core competitiveness and long-term development to break through the bottleneck of development and find the direction of transformation and greater profitability through transformation (Blumenthal and Haspeslagh, 1994). Therefore, enterprise transformation can enable companies to obtain great corporate performance.

The existing literature has pointed out the relationship between enterprise transformation and corporate performance. Kaplinsky and Morris (2003) distinguished and explained the relationship between enterprise transformation and corporate performance resulting from transformation. By distinguishing the types of transformation, Qiu and Liu (2015) pointed out that product upgrading could directly contribute to corporate performance or indirectly affect the increase of corporate performance by promoting technological innovation; while functional upgrading had a positive impact on corporate performance only through technological innovation. The positive impact of functional upgrading on corporate performance can only occur through technological innovation, and functional upgrading without technological innovation will have a negative impact on corporate performance. As a result, we propose the hypothesis that.

H4: Enterprise transformation is positively related to corporate performance.

\section{The Driving Role of Market Pressure}

In the competitive modern market, enterprises integrate internal conditions and external environmental resources and need to balance the interests of stakeholders' needs in order to seek long-term survival and development.

Therefore, enterprises bring a huge market pressure for meeting the stakeholder's interest needs, which forces them to actively respond to innovation and pay attention to scientific and technological issues in the market competition. By further research, Eiadat et al. (2008) argued that technological innovation not only positively affected the growth of corporate performance and the winning of competitive advantage, but also responded to pressures from the market side (including consumers, suppliers, and peer competitors). Jennings (1995) stated that demand pressure from stakeholders, both internal and external to the firm, would force firms to focus on innovation issues and take the initiative to engage in technological innovation. Zhai and Bi (2016) pointed out through a study of listed high-tech enterprises that when firms faced market pressure, the driving force of exploratory innovation investment and developmental innovation investment would be correspondingly increased through meta-innovation investment, with developmental innovation investment playing a much obvious role. From the perspective of asset specificity, $\mathrm{Xu}$ et al. (2015) found that although there was a significant difference in market pressure faced by different firms, as the investment in research and development increased, the firm would win the competitive advantage and excess profit.

In view of this, the following hypotheses are proposed in this study:
H5: Market pressure is positively related to technological innovation.
H6: Market pressure is positively related to corporate performance.

In addition, the continued intensification of competition will also have technology or products that are difficult to create longterm revenue for the company, which will lead to the further expansion of the market pressure faced by the company. As the pressure continues to increase, firms, in order to gain great revenue and sustained competitive advantage, will then make enterprise transformation or upgrade through technological innovation, thus successfully avoid market pressure ( $\mathrm{Li}$ et al., 2005). Under the pressure of market competition and market pressure, enterprises will make fundamental transformation and changes to their business direction, strategic structure, and resource allocation, in an attempt to alleviate competition and market pressure, enhance social value and regain competitive advantage.

Many scholars have conducted research on this subject, expecting to help companies to survive the crisis and transform successfully. Clemons and Hann (1999) clearly argued that regular transformation of most firms had become increasingly important in the current competitive market. Mao and Wang (2006) pointed out through a study of local enterprises that enterprise transformation was a unique phenomenon in emerging economies because enterprises in emerging economies were facing greater market pressure than those in developed countries, and the study also pointed out that intense market pressures are also opportunities and spaces for corporate transformation and upgrading. Zhou and Yang (2013) took Guangdong foreign trade enterprises as the research object and found through structural equation modeling that the market pressure of SMEs and large enterprises had significant influence on the aspects of enterprise transformation and government policy support, but their current difficulties, transformation direction, and policy needs and other pressures had significant differences, so the government needed to introduce appropriate support policies according to the specific situation of different types of enterprises.

Based on this, we propose the following hypothesis.

H7: Market pressure is positively related to enterprise transformation.

\section{The Driving Role of Competitive Advantage}

Resource-based theory suggests that the optimal combination and reallocation of a firm's valuable, scarce, and inimitable resources is an important source of gaining competitive 
advantage (Barney et al., 2001). The key resources and key capabilities that companies have are the foundation for enterprise transformation and the starting point and beginning of enterprise transformation (Makadok, 2001; Makadok and Barney, 2001). Therefore, full understanding and judgment of key resources and capabilities is an important part of enterprise competitive advantage identification. As the competitive advantage of enterprise transformation, abundant key resources and capabilities become the antecedent determinants of enterprise transformation, which is an important prerequisite for enterprises to carry out transformation. On the one hand, capital accumulation, as a key resource, is conducive to the success of enterprise transformation by improving the level of technological innovation, enhancing product brand image, and establishing independent brands through good corporate performance (Forbes and Wield, 2002). On the other hand, the impact of different types of resources on corporate performance varies. The impact of resources underlying strategic alliances on corporate performance occurs under uncertain conditions of technological innovation or when the level of product innovation is low, and competitive advantage has a significant impact on market performance (Murray and Greenes, 2006). Strategic alliance partner resources act on the choice between partners and influence the adaptation between partners through partner choice, which in turn synergistically affects the performance of alliance business strategies (Luo, 1997). Remodeling the organizational structure and matching corporate resources facilitate the speed of transformation, capturing key factors of enterprise transformation such as management culture and innovation culture, reducing strategic restructuring and generating benefits, improving corporate performance, and gaining competitive advantage (Luo and Chi, 2005).

Competitive advantage can continuously create added value for customers, win customer satisfaction and loyalty, and obtain superior corporate performance over competitors. Protogerou et al. (2011) argued that competitive advantage could continuously create superior value for customers and enable firms to achieve superior performance, and further pointed out that competitive advantage led to performance including not only financial performance but also non-financial performance, such as product quality, customer satisfaction, etc. Wang (2016) showing that corporate core competencies had a positive effect on corporate performance. Through a questionnaire survey of 296 firms in China, and the results of the analysis with structural equation modeling and partial least squares, they found that corporate core competencies were a mediating variable of information technology affecting corporate performance. Therefore, we propose the following hypotheses.

H8: Competitive advantage is positively related to enterprise transformation.

H9: Competitive advantage is positively related to corporate performance.

In summary, this study proposes a research model as shown in Figure 1.

\section{MATERIALS AND METHODS}

\section{Participants and Procedure}

In this study, real estate companies and construction companies are selected as the research samples. The reasons are as follows, First, because the construction industry is currently facing the bottleneck of rising energy efficiency in buildings, and the in-depth promotion of transformation has become an important way for it to break through the bottleneck and achieve green and high-quality development. Second, due to the significant structural changes in the real estate market and the adjustment of relevant national policies, transformation has become a new development direction being explored by the real estate industry. Therefore, it is of more practical value to study the industry and enterprises where transformation is imperative. The questionnaires of this study are targeted at middle and senior managers of enterprises. The data collection of this study is completed through two rounds of questionnaire survey.

The first round of research, which started at the end of March and lasted until the end of June 2021, selected five real estate enterprises, and a total of 230 middle and senior managers in the real estate industry participated in the questionnaire survey, and a total of 208 valid questionnaires were obtained. The second round of research, which started from the beginning of July and lasted until the end of August 2021, selected five construction enterprises, and a total of 220 middle and senior managers of the construction industry participated in the questionnaire survey, and a total of 193 valid questionnaires were obtained. A total of 401 valid samples were obtained in the two rounds of research. Among them, $75.56 \%$ was male, $89.56 \%$ under 45 years old, $2.89 \%$ over 60 years old, $13.78 \%$ of master's degree and above, $52.22 \%$ of bachelor's degree, and $34 \%$ of specialist and below. Middle-level managers accounted for $66 \%$ and senior managers accounted for $34 \%$; in terms of years of work in the positions held, $44.23 \%$ was below 5 years, $30.66 \%$ above 5 years and within 10 years, and $25.11 \%$ above 10 years.

\section{Measures}

First, to ensure the reliability and validity of the measurement scales, the measurement questions in this study are all based on existing established scales, which are organized according to the research objectives through literature analysis. Among them, the scales from SSCI journals are translated and validated according to the recommendations of the back-translation method to ensure the quality of the questionnaire and its applicability in Chinese context. Second, to ensure the expert validity of the measurement questionnaire, five scholars in the field of transformation research and three corporate executives engaged in enterprise transformation are invited to review the questionnaire, which is finally formed through the joint suggestions from the academic and corporate practice communities. Third, the measurement questionnaire of this study consists of 23 items, and the measurement items are all measured using a Likert 7-point scale. The variables are measured as follows. 


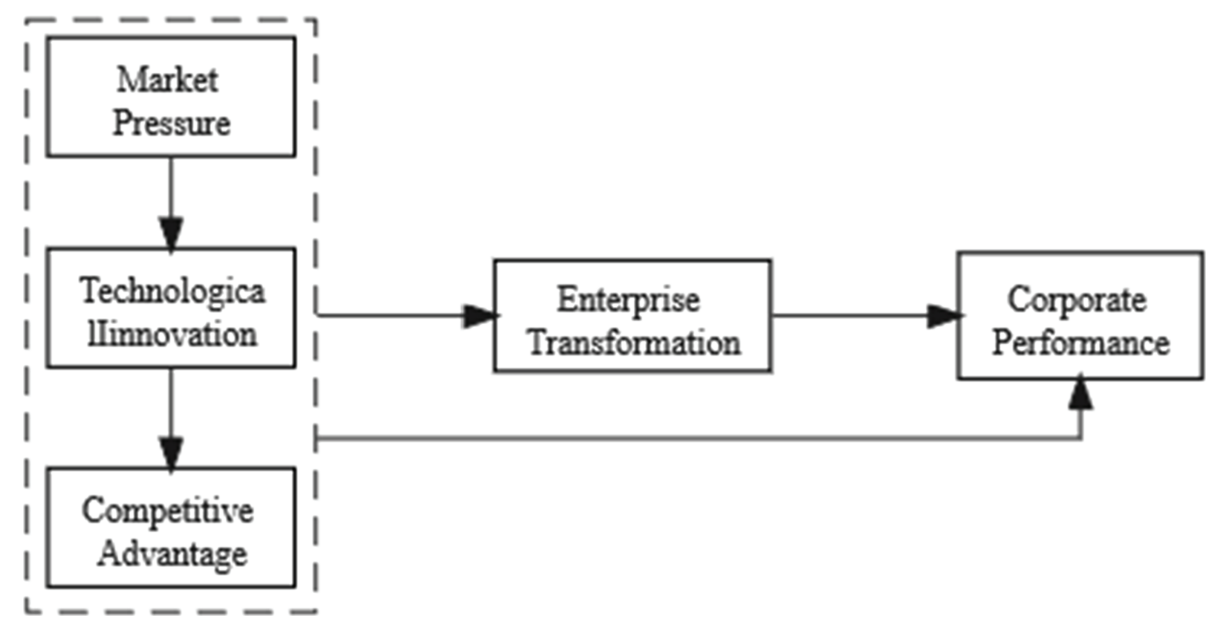

FIGURE 1 | Theoretical model.

- Technological innovation: this study refers to the technological innovation research scale of Nietoa and Quevedo (2005), Xu et al. (2018), and Wang (2016), which consists of five questions, such as "the proportion of the company's investment in technological innovation equipment is increasing" and "the proportion of the company's technological innovation personnel to all R\&D personnel is gradually increasing."

- Corporate performance: this paper draws on the studies of Antoncic et al. (2007) and Jaakko et al. (2010). The scale consists of four questions, such as "the growth rate of the company's market share is increasing year by year" and "the overall market competitiveness of the company's products is higher than that of its main competitors in the same industry."

- Enterprise transformation: In this paper, drawing on the studies of Jaworski and Kohl (1993), Li et al. (2008), and Jia and Zhao (2014), the scale consists of five questions, with sample questions such as "This enterprise can grasp the time of transformation in a timely manner," "This enterprise has invested relative financial resources in transformation." The scale consists of five items, such as "The company can grasp the transformation time in time" and "The company has invested relative resources in the transformation."

- Market pressure: this article draws on the studies of Tang and Tang (2012), Wang et al. (2010a), and Cao and Chen (2017), with four questions. The sample questions are "Most of our customers have higher and higher demands on product quality" and "Most of our customers are very concerned about the development of new products in our company."

- Competitive advantage: in this study, the scale consists of five questions, as studied by Dong et al. (2011) and Ma et al. (2014). Sample questions include "Compared with competitors, this company can provide products or services to customers at a lower cost," "Compared with competitors, this company can provide multifunctional and highperformance products or services to customers," etc.
- Control variables: in this study, the subjects' gender, age, education, and years of job tenure are selected as control variables.

\section{DATA ANALYSIS}

\section{Common Method Variance}

Common method variance (CMV) is an overestimation of interconstrual correlations due to self-reported scales and is also influenced by the same measurement method, which reduces the variance between different constructs (Xu, 2015). Thus, CMV is the error of the measurement instrument and measurement error affects the validity of the conclusions of measuring the relationship between constructs (Podsakoff et al., 2003).

CMV post hoc detection can be handled by applying SEM, where different conformational variables are analyzed using a single CFA model, where a good correlation between conformations means that there is CMV and CFA yields a good fitness (Korsgaard and Roberson, 1995; Mossholder et al., 1998). Single CFA assessed the increase in CMV to CMV nested competition pattern, its complexity and assessed whether the increase in cardinality is significant (Podsakoff and Organ, 1986; McFarland and Sweeny, 1992). Single CFA analysis shows that $\chi^{2}=2130.080$ and $\mathrm{DF}=230$, multi-factor CFA analysis shows that $\chi^{2}=563.311$ and $\mathrm{DF}=220$, two models $\Delta \mathrm{DF}=230-220=10$ and $\Delta \chi^{2}=2130.080-563.311=1566.769$, and their significance is calculated by applying distcale software. The significant difference $p<0.00$, indicates that the null hypothesis is rejected, so the two models are not different and no common method deviation exists between the conformational surfaces, and the results are shown in Table 1 .

\section{Confirmatory Factor Analysis}

CFA is a part of SEM analysis. The variable reduction of CFA measurement model in this study is based on Zhang et al. (2021) 
TABLE 1 | Comparison of single-factor and multi-factor model.

\begin{tabular}{lcc}
\hline Model & Single-factor CFA & Multi-factor CFA \\
\hline$D F$ & 230 & 220 \\
$\triangle D F$ & & 10 \\
$\chi^{2}$ & 2130.080 & 563.311 \\
$\triangle \chi^{2}$ & & 1566.769 \\
\hline
\end{tabular}

two-stage model modification (Anderson and Gerbing, 1998). The measurement model must be tested before performing the structural model evaluation. A complete SEM model report can only be carried out if the measurement model is reasonably acceptable (Kline, 2005).

In this study, CFA analysis is performed on all dimensions, and the results are shown in Table 2 . The standardized factor loadings of all dimensions are between 0.693 and 0.862 , the composite reliability is between 0.843 and 0.912 , and convergence validity is between 0.575 and 0.675 , meeting all the standards of Fornell and Lacker (1981) with standardized factor loadings greater than 0.50 , composite reliability greater than 0.60 , and convergence validity greater than 0.50 (Verbeke et al., 2014; Hair et al., 2017). Therefore, the model meets the standard, and all aspects have good convergence validity.

\section{Discriminant Validity}

The discriminant validity analysis is to examine whether two different variables in the statistics are different or not. In this study, the AVE method is used to evaluate the discriminative validity. Fornell and Lacker (1981) propose the square root of the AVE with the correlation between the construct and other constructs in the model, which means that the variables have discriminative validity. As shown in Table $\mathbf{3}$, the square roots of the AVE on the diagonal are larger than the correlations between constructs, indicating acceptable discriminant validity. Therefore, this study has good discriminative validity.

\section{Model Fit Degree}

The structural model analysis is performed by the method of great likelihood estimation, and the analysis results include model fit, significance test of the research hypotheses, and interpretable variance $\left(R^{2}\right)$. The research hypothesis of SEM is sample covariance matrix $=$ model covariance matrix. However, SEM is a large sample analysis method, so the value of $p$ is very easy to be less than 0.05 and often wrongly reject the hypothesis and get the conclusion that the model is not good, so Kline (2011) and Schumacker and Lomax (2010) suggested that the degree of model fit should not be determined by the value of $p$, but to report a variety of different fit indicators to determine whether the model fit is good.

The fit metrics in this study apply the 194 international academic journal (SSCI) papers explored in the study of Jackson et al. (2009) as a blueprint for applying model fit analysis and report the results of this study with nine most widely used fit metrics. These include ML $\chi^{2}, \mathrm{DF}$, Normed Chi-sqr $\left(\chi^{2} / \mathrm{DF}\right)$, RMSEA, SRMR, TLI (NNFI), CFI, GFI, and AGFI. The results of the Bollen-Stine Bootstrap corrected model fit, and the Bollen-Stine Bootstrap corrected model fit are shown in Table 4.
After that, all the fit metrics of this study have passed, showing that the results of this study are acceptable models.

\section{Regression Coefficient}

In this research model (as shown in Table 5), market pressure (MP; $b=0.581, p<0.001$ ) significantly affects technological innovation (TI), technological innovation (TI; $b=0.665, p<0.001$ ) significantly affects competitive advantage (CA). Competitive advantage (CA; $b=0.281, p<0.001$ ), technological innovation (TI; $b=0.304, p<0.001$ ) and market pressure (MP; $b=0.207, p<0.001)$ significantly affect enterprise transformation (ET), technological innovation (TI; $b=0.206, p<0.001$ ), market pressure (MP; $b=0.352, p<0.001$ ), competitive advantage $(\mathrm{CA} ; b=0.156, p<0.001)$ and enterprise transformation (ET; $b=0.231, p<0.001)$ significantly affect corporate performance (CP). Therefore, all hypotheses are established.

\section{Multiple-Group Analysis}

In this study, we want to understand whether there is a significant difference between the effects of the two industries of construction and real estate in the model constructs, so we use the comparison of clusters in the structural equation model (Deng et al., 2008; Abram et al., 2017) and analyze the results of the estimation of each of the two groups of people in the structural equation model in the construction industry and real estate industry respectively, followed by setting the regression coefficients of the two groups to be equal, and if the value of $p$ of the check results is less than 0.05 , indicating that the two slopes are significantly different, and vice versa (Pousette and Hanse, 2002; Smith et al., 2016). The analysis is organized into Table 6, there are nine regression coefficients in the model, and the results of the analysis of the construction and real estate industries are shown in the table, and the comparison result $Z>1.96$ indicates that there is a significant difference between the regression coefficients of the two groups in the construction and real estate industries. It can be seen that there are five groups with significant differences in the study results, which are the effect of competitive advantage on enterprise transformation, the effect of technological innovation on enterprise transformation, the effect of technological innovation on corporate performance, and the effect of technological innovation on corporate performance, technological innovation on corporate performance, market pressure on corporate performance, and competitive advantage on corporate performance. The rest of the paths are not significant.

\section{RESULTS}

\section{Research Conclusion}

This study examines the drivers of local enterprise transformation in China and its internal and external influencing mechanisms by taking middle and senior managers in the real estate and construction industries as the research subjects. Based on the results of the empirical analysis of structural equation modeling, this study provides a more complete explanation of the mechanisms and influencing factors of the local enterprise transformation in China under COVID-19. 
TABLE 2 | Confirmatory factor analysis.

\begin{tabular}{|c|c|c|c|c|c|c|c|c|c|}
\hline \multirow[t]{2}{*}{ Construct } & \multirow[t]{2}{*}{ Item } & \multicolumn{3}{|c|}{ Significance of Estimated Parameters } & \multicolumn{3}{|c|}{ Item Reliability } & \multirow{2}{*}{$\begin{array}{c}\text { Construct } \\
\text { Reliability }\end{array}$} & \multirow{2}{*}{$\begin{array}{c}\begin{array}{c}\text { Convergence } \\
\text { Validity }\end{array} \\
A V E\end{array}$} \\
\hline & & Unstd. & $S E$ & value of $z$ & value of $p$ & Std. & $S M C$ & & \\
\hline \multirow[t]{3}{*}{$\mathrm{TI}$} & TI1 & 1.000 & & & & 0.719 & 0.517 & 0.843 & 0.575 \\
\hline & $\mathrm{T} 12$ & 1.064 & 0.069 & 15.346 & $* * *$ & 0.797 & 0.635 & & \\
\hline & TI3 & 1.106 & 0.071 & 15.512 & $* * *$ & 0.807 & 0.651 & & \\
\hline & MP2 & 1.068 & 0.064 & 16.812 & $* * *$ & 0.815 & 0.664 & & \\
\hline & MP3 & 1.052 & 0.064 & 16.549 & $* * *$ & 0.802 & 0.643 & & \\
\hline & MP4 & 1.012 & 0.063 & 16.109 & $* * *$ & 0.782 & 0.612 & & \\
\hline & MP5 & 1.033 & 0.063 & 16.467 & $* * *$ & 0.798 & 0.637 & & \\
\hline \multirow[t]{3}{*}{$\mathrm{CA}$} & CA1 & 1.000 & & & & 0.790 & 0.624 & 0.912 & 0.675 \\
\hline & CA2 & 1.064 & 0.053 & 20.129 & $* * *$ & 0.862 & 0.743 & & \\
\hline & CA3 & 1.011 & 0.055 & 18.412 & $* * *$ & 0.804 & 0.646 & & \\
\hline & ЕT3 & 1.079 & 0.070 & 15.374 & $* * *$ & 0.799 & 0.638 & & \\
\hline & TET4 & 1.120 & 0.072 & 15.659 & $* * *$ & 0.815 & 0.664 & & \\
\hline & ET5 & 1.062 & 0.070 & 15.157 & $* * *$ & 0.786 & 0.618 & & \\
\hline \multirow[t]{4}{*}{$\mathrm{CP}$} & $\mathrm{CP} 1$ & 1.000 & & & & 0.693 & 0.480 & 0.843 & 0.575 \\
\hline & CP2 & 1.071 & 0.073 & 14.696 & $* * *$ & 0.787 & 0.619 & & \\
\hline & $\mathrm{CP} 3$ & 1.111 & 0.075 & 14.782 & $* * *$ & 0.792 & 0.627 & & \\
\hline & CP4 & 1.003 & 0.071 & 14.188 & $* * *$ & 0.756 & 0.572 & & \\
\hline
\end{tabular}

STD, Standardized Factor Loadings; SMC, Square Multiple Correlations; CR, Composite Reliability; AVE, Average Variance Extracted; TI, Technological Innovation; MP, Market Pressure; CA, Competitive Advantage; ET, Enterprise Transformation; CP, Corporate Performance. *** $p<0.001$.

TABLE 3 | Discriminant validity.

\begin{tabular}{lccccc}
\hline & AVE & MP & TI & CA & ET \\
MP & 0.621 & $\mathbf{0 . 7 8 8}$ & & & \\
TI & 0.575 & 0.560 & $\mathbf{0 . 7 5 8}$ & $\mathbf{0 . 8 2 2}$ & \\
CA & 0.675 & 0.344 & 0.614 & 0.636 & $\mathbf{0 . 7 7 6}$ \\
ET & 0.602 & 0.539 & 0.685 & 0.600 & 0.703 \\
CP & 0.575 & 0.689 & 0.708 & $\mathbf{0 . 7 5 8}$ \\
\hline
\end{tabular}

The items on the diagonal on bold represent the square roots of the AVE. Off-diagonal elements are the correlation estimates. TI, Technological Innovation; MP, Market Pressure; CA, Competitive Advantage; ET, Enterprise Transformation; CP, Corporate Performance.

TABLE 4 | Model fit criteria and test results.

\begin{tabular}{llc}
\hline Model fit & Criteria & $\begin{array}{c}\text { Model fit of research } \\
\text { model }\end{array}$ \\
\hline ML $\chi^{2}$ & The small the better & 467.594 \\
DF & The large the better & 221 \\
Normed Chi-sqr $\left(\chi^{2} / \mathrm{DF}\right)$ & $1<\chi^{2} / \mathrm{DF}<3$ & 2.12 \\
RMSEA & $<0.08$ & 0.05 \\
SRMR & $<0.08$ & 0.07 \\
TLI (NNFI) & $>0.9$ & 0.96 \\
CFI & $>0.9$ & 0.96 \\
GFI & $>0.9$ & 0.93 \\
AGFI & $>0.9$ & 0.91 \\
\hline
\end{tabular}

First, Validated the role of internal and external factors in influencing firm transformation. This study shows that technological innovation and its internal and external environment have significant theoretical explanatory power for China's enterprise transformation. Although theoretical studies on enterprise transformation in developed countries are abundant and have become a hot topic of social concern, research on enterprise transformation in China, especially empirical studies, is extremely limited. In view of the differences in enterprise management in terms of market operating environment, management philosophy, and business practices, it is necessary to examine the drivers of enterprise transformation and its performance in China from a theoretical perspective. Based on the theoretical foundation and literature review, this study examines the effects of market pressure, technological innovation, and competitive advantage on enterprise transformation in the Chinese context. Overall, market pressure, technological innovation, and competitive advantage are important antecedent influences on enterprise transformation and have positive effect on enterprise transformation. Among them, technological innovation is a very important predictor and main path of enterprise transformation. It is also found that technological innovation positively influences the competitive advantage of the 
TABLE 5 | Regression coefficient.

\begin{tabular}{llllccc}
\hline DV & IV & Unstd & SE & Unstd./SE & value of $\boldsymbol{p}$ & Std. \\
\hline TI & MP & 0.581 & 0.062 & 9.433 & $* * *$ & 0.56 \\
CA & TI & 0.665 & 0.063 & 10.538 & $* * *$ & 0.614 \\
ET & CA & 0.281 & 0.046 & 6.162 & $* * *$ & 0.346 \\
& TI & 0.304 & 0.059 & 5.114 & $* * *$ & 0.345 \\
& MP & 0.207 & 0.047 & 4.375 & $* * *$ & 0.226 \\
CP & TI & 0.206 & 0.06 & 3.43 & $* * *$ & 0.228 \\
& MP & 0.352 & 0.051 & 6.868 & $* * *$ & 0.375 \\
& CA & 0.156 & 0.046 & 3.42 & $* * *$ & 0.187 \\
& ET & 0.231 & 0.067 & 3.478 & $* * *$ & 0.225 \\
\hline
\end{tabular}

$* * * p<0.001$

TI, Technological Innovation; MP, Market Pressure; CA, Competitive Advantage; ET, Enterprise Transformation; CP, Corporate Performance.

TABLE 6 | Multiple-group comparison regression coefficients.

\begin{tabular}{|c|c|c|c|c|c|c|c|c|}
\hline \multirow{2}{*}{ DV } & \multirow{2}{*}{ IV } & \multicolumn{2}{|c|}{ Construction } & \multicolumn{2}{|c|}{ Real estate } & \multicolumn{3}{|c|}{ Regression weight comparison } \\
\hline & & Estimate & $S E$ & Estimate & $S E$ & diff. & value of $z$ & value of $p$ \\
\hline CA & $\mathrm{TI}$ & 0.903 & 0.119 & 0.696 & 0.091 & 0.207 & 1.384 & 0.167 \\
\hline \multirow[t]{2}{*}{ ET } & $\mathrm{CA}$ & 0.203 & 0.052 & 0.806 & 0.124 & -0.603 & 4.5 & 0 \\
\hline & $\mathrm{TI}$ & 0.499 & 0.105 & -0.1 & 0.1 & 0.599 & 4.133 & 0 \\
\hline \multirow{3}{*}{$\mathrm{CP}$} & MP & 0.417 & 0.07 & -0.059 & 0.116 & 0.476 & 3.499 & 0.001 \\
\hline & $\mathrm{CA}$ & -0.042 & 0.056 & 1.046 & 0.29 & -1.088 & 3.679 & 0 \\
\hline & ET & 0.212 & 0.119 & -0.029 & 0.26 & 0.241 & 0.84 & 0.402 \\
\hline
\end{tabular}

TI, Technological Innovation; MP, Market Pressure; CA, Competitive Advantage; ET, Enterprise Transformation; CP, Corporate Performance.

firm and is also positively influenced by market pressure, which together affects the transformation. In addition, market pressure (MP; $b=0.207, p<0.001)$ also plays a positive role in enterprise transformation. Meanwhile, the positive driving effect of technological innovation on enterprise transformation is more significant than that of competitive advantage and market pressure. Internal and external antecedents have a significant positive effect on corporate performance.

Second, Validated the mechanism of the impact of enterprise transformation on corporate performance. This study shows that corporate transformation has a significant effect on corporate performance, however, the driving effect of enterprise transformation motivation and its performance overall consideration varies significantly. On the one hand, there are differences in the driving effects of antecedent influences of enterprise transformation. The structural equation modeling analysis revealed that competitive advantage $(b=0.281, p<0.001)$, technological innovation $(b=0.304, p<0.001)$ and market pressure $(b=0.207, p<0.001)$ had significant effects on enterprise transformation (ET). The results show that competitive advantage $(\mathrm{CA} ; b=0.281, p<0.001)$ is a significant external antecedent influence on enterprise transformation and has a significant contribution to enterprise transformation. On the other hand, the path analysis through structural equation modeling shows that there are differences in the driving effects of the antecedent influences of corporate performance. Specifically, the situation is as follows. First, market pressure (MP; $b=0.352, p<0.001$ ), and competitive advantage $(\mathrm{CA} ; b=0.156, p<0.001)$ are important external influences on corporate performance, but market pressure has a greater impact on corporate performance than competitive advantage and is the main external source of corporate performance growth. Second, enterprise transformation (ET; $b=0.231, p<0.001$ ), technological innovation (TI; $b=0.206, p<0.001)$ are important internal influences on corporate performance, but enterprise transformation has a greater positive effect on corporate performance than technological innovation and is an important internal source of corporate performance growth. Internal and external antecedents have a significant positive effect on corporate performance. Internal and external important antecedents jointly drive the growth of corporate performance.

Third, revealed the significant differences of transformation mechanism between real estate and construction industries in terms of transformation. The multiple-group analysis reveals that the overall mechanism of action based on technological innovation has different effects on real estate and construction industries. Specifically, there are five groups of regression coefficients with significant differences between real estate and construction firms, namely, the driving effect of competitive advantage on transformation, the driving effect of technological innovation on enterprise transformation, the driving effect of technological innovation on corporate performance, market pressure on corporate performance, and competitive advantage on corporate performance; the remaining four groups, namely, the effect of market pressure on technological innovation, the 
effect of technological innovation on competitive advantage, the effect of market pressure on transformation, and the effect of enterprise transformation on corporate performance. The effect of transformation on corporate performance is not significant. This shows that there are significant differences in the effects of market pressure, technological innovation, and competitive advantage on corporate performance. Among them, the significance of competitive advantage on corporate performance is significantly stronger in the real estate industry than in the construction industry, while the effects of technological innovation and market pressure on corporate performance are stronger in the construction industry than those in the real estate industry. The effects of technological innovation and market pressure on corporate performance in the construction industry are stronger than those in the real estate industry. Meanwhile, there are significant differences in the effects of competitive advantage and technological innovation on enterprise transformation. Among them, the driving effect of technological innovation on enterprise transformation is stronger in construction than that in real estate industry, while the driving effect of competitive advantage on enterprise transformation is stronger in real estate industry than that in construction industry.

\section{Theoretical Contributions}

First, it promotes the overall study of the antecedents and consequences of the mechanism of enterprise transformation. This study analyzes the core factors driving enterprise transformation from the perspective of enterprise transformation drivers, and proposes the overall influence of market pressure, technological innovation and competitive advantage on enterprise transformation, while technological innovation is driven by market pressure and transformed into competitive advantage. In particular, technological innovation is considered as an important antecedent driver of enterprise transformation under the constraints of market pressure and driven by competitive advantage, and the outcome of enterprise transformation, that is, corporate performance, is considered. The findings of this study help to better understand the root causes of enterprise transformation and evaluate the results and provide guidance for companies to further understand and transform their business practices to improve corporate performance and market competitiveness.

Second, it promotes the contribution to enterprise transformation theory. This study examines the mechanism of transformation through empirical research from a holistic perspective of enterprise transformation motivation and performance. Whether enterprises can make full use of technological innovation and turn it into opportunities and drivers of enterprise transformation requires the overall driving force of market pressure, technological innovation, and competitive advantage. When making transformation decisions, enterprises should consider the positive impact of technological innovation, market pressure on technological innovation, and the competitive advantage brought by technological innovation. In order to realize the synergistic effect of the overall driving factors and to lay a solid foundation for enterprise transformation to achieve superior performance, we should consider the three aspects as a whole.

\section{Practical Implications}

The issue of China's local enterprise transformation needs urgent attention. The details are as follows.

First, the most important thing is that, with the transformation of China's economic structure and the increasingly difficult environment for enterprises to survive, more and more enterprises are seeking survival and development through transformation, and the number of enterprises undergoing transformation is bound to increase. Although China's enterprise transformation space is huge, the causes and consequences of transformation have not received due attention, if not timely enterprise transformation of the important antecedent factors and their driving effect of all-round, multi-level research, it is very likely to ignore the pressure of transformation, and thus produce the negative impact of transformation, which is the failure of enterprises aspiring to obtain excellent performance through transformation practice. In addition, enterprise managers should pay attention to the role of internal and external factors on enterprise transformation. This study finds that technological innovation, actively driven by market pressure, has the greatest effect on enterprise transformation, and is also the greatest factor affecting corporate performance. Since technological innovation is the heavy source driving enterprise transformation, companies should break through the bottlenecks affecting technological innovation, enhance their core competitiveness by developing core technologies, and promote enterprise. More importantly, the enterprise transformation in different industries is the most important factor in the value chain.

Second, there are significant differences in the driving effect of enterprise transformation in different industries. We should not simply base on the driving effect of enterprise transformation, but should guide the practice of enterprise transformation for different industries by combining their own industry characteristics and market conditions.

For the construction industry, the positive impact of technological innovation on enterprise transformation and corporate performance is more significant, and enterprise transformation should take advantage of it. We should focus on using technological innovation to drive enterprise transformation. In other words, the success of corporate transformation is caused by increasing the investment in technological innovation, thus reducing the pressure of corporate transformation and obtaining greater corporate performance. At the same time, the positive effect of market pressure on corporate performance should be properly utilized, that is, the market pressure faced by the company should be turned into the motivation for corporate transformation, which will lead to the growth of corporate performance instead of the decline of performance.

For the real estate industry, the driving effect of competitive advantage on enterprise transformation and corporate performance is more significant than that of the construction industry, and enterprise transformation should take advantage of this. Therefore, enterprises in the real estate industry should pay more attention to the positive influence of competitive advantage while giving full play to the advantages of technological innovation and transforming the disadvantages of market pressure. In the increasingly competitive real estate industry under the market 
economy, companies with competitive advantage often become the winners. This is because when a company undergoes transformation, the more prominent competitive advantage can help the company reduce the pressure of upgrading and gain the ability to cope with environmental challenges. If a real estate company implements a competitive strategy that is difficult or too costly for its competitors to imitate, it gains a sustainable competitive advantage. For example, Wanda Commercial Real Estate's business model innovation based on the smile curve theory is representative of a company that gains long-term competitive advantage and earns above-average profits. A real estate company with a competitive advantage can win the market and achieve above-average profits with good growth prospects, while a company without a competitive advantage will be outperformed by its competitors and suffer from mediocre corporate performance.

\section{Research Limitations and Future Research Directions}

Although this study strictly follows the requirements of the questionnaire and empirical research to conduct multi-group analysis, the research perspective and ideas have certain advantages over existing studies and have practical significance for enterprise transformation activities, there are still some limitations for improvement. First, there are limitations in the sample source of this study. The questionnaire survey of middle and senior managers around "enterprise transformation" is in itself a complex and difficult topic. However, future research can expand the scope of data collection and conduct structural equation modeling with larger samples to enhance the generalizability of the research results.

\section{REFERENCES}

Abram, P. K., Hoelmer, K. A., Acebes-Doria, A., Andrews, H., and Beers, E. H. (2017). Indigenous arthropod natural enemies of the invasive brown marmorated stink bug in North America and Europe. J. Pest. Sci. 90, 1009-1020. doi: 10.1007/s10340-017-0891-7

Amsden, A. H. (1989). Asias next Giant-how Korea competes in the worldeconomy. Technol. Rev. 92, 46-53.

Anderson, J. C., and Gerbing, D. W. (1998). Structural equation modeling in practice: a review and recommended two-step approach. Psychol. Bull. 103, 411-423. doi: 10.1037/0033-2909.103.3.411

Antoncic, B., Prodan, I., and Hisrich, R. D. (2007). Technological innovativeness and firm performance in Slovenia and Ronania. Post-Communist Econ. 19, 281-298. doi: 10.1080/14631370701503299

Barney, J., Wright, M., and Ketchen, D. J. (2001). The resource-based view of the firm, ten years after 1991. J. Manag. 27, 625-641. doi: 10.1177/014920 630102700601

Bell, M., and Albu, M. (1999). Knowledge systems and technological dynamism in industrial clusters in developing countries. World Dev. 27, 1715-1734. doi: 10.1016/S0305-750X(99)00073-X

Bi, K. X., Fu, S. N., Yang, C. J., and Li, Y. (2017). Study on the interaction between manufacturing industry upgrading and low-carbon technology breakthrough innovation. China Soft Sci. 12, 141-153. doi: 10.1109/ ICMSE.2017.8574386

Blumenthal, B., and Haspeslagh, P. (1994). Toward a definition of corporate transformation. Sloan Manag. Rev. 35, 101-106.

Cao, L. L. (2020). Changing port governance model, port spatial structure and trade efficiency. J. Coastal Stu. 95, 963-968. doi: 10.2112/SI95-187.1
Second, there are limitations in the sample sources of clusters in this study. Although this study is an advanced paradigm of cluster comparison analysis, which has significant superiority over general empirical studies, the cohort of this study is limited to the construction and real estate industries only, and future studies can collect data in a wider range of industries, such as small and medium-sized enterprises, private technology-based enterprises, manufacturing and other representative industries of transformation, and conduct hierarchical linear modeling studies in a larger industry cluster to enhance the generalizability of the study results.

\section{DATA AVAILABILITY STATEMENT}

The raw data supporting the conclusions of this article will be made available by the authors, without undue reservation.

\section{ETHICS STATEMENT}

Ethical review and approval was not required for the study on human participants in accordance with the local legislation and institutional requirements. Informed consent was obtained from all subjects involved in the study.

\section{AUTHOR CONTRIBUTIONS}

HS and TH: conceptualization. HS and ZD: data curation, formal analysis, and investigation. $\mathrm{HS}, \mathrm{TH}$, and SK: writing original draft and writing - review and editing. All authors have read and agreed to the published version of the manuscript.

Cao, H. J., and Chen, Z. W. (2017). The driving effect of internal and external environment on firms' green innovation strategies - the moderating role of executives' environmental awareness. Nankai Manage. Rev. 20, 95-103. doi: 10.19744/j.cnki.11-1235/f.2017.06.018

Clemons, E. K., and Hann, I. H. (1999). Hann. Rosenbluth international, strategic transformation of a successful Enterprise. J. Manag. Inf. Syst. 16, 9-27. doi: 10.1080/07421222.1999.11518243

Cohen, W. M. (2010). Fifty years of empirical studies of innovative activity and performance. Handbook Eco. Innov. 1, 129-213. doi: 10.1016/ S0169-7218(10)01004-X

Crossa, M. (2021). Contorting transformations, uneven impacts of the USMexico automotive industrial complex. Comp. Change:102452942110454. doi: $10.1177 / 10245294211045453$

Deng, X., Doll, W. J., Al-Gahtani, S. S., Larsen, T. J., and Pearson, J. M. (2008). A cross-cultural analysis of the end-user computing satisfaction instrument, A multi-group invariance analysis. Inf. Manag. 45, 211-220. doi: 10.1016/j. im.2008.02.002

Dong, B. B., Ge, B. S., and Wang, K. (2011). Resource integration process, dynamic capabilities and competitive advantage, mechanisms and paths. Manage. World 3, 92-101. doi: 10.3969/j.issn.1002-5502.2020.06.014

Efogo, F. O. (2020). Does trade in services improve African participation in global value chains. African Dev. Rev. 32, 758-772. doi: 10.1111/1467-8268.12476

Eiadat, Y., Kelly, A., Roche, F., and Eyadat, H. (2008). Green and competitive? An empirical test of the mediating role of environmental innovation strategy. J. World Bus. 43, 131-145. doi: 10.1016/j.jwb.2007.11.012

Forbes, N., and Wield, D. (2002). From Followers to Leaders, Managing Technology and Innovation in Newly Industrializing Countries. United Kingdom: Psychology Press. 
Fornell, C. R., and Lacker, D. F. (1981). Evaluating structural equation models with unobservable variables and measurement error. J. Mark. Res. 18, 39-50. doi: $10.1177 / 002224378101800104$

Fu, S. K., Ma, Z., Ni, B., Peng, J. C., Zhang, L. J., and Fu, Q. (2021). Research on the spatial differences of pollution-intensive industry transfer under the environmental regulation in China. Ecol. Indic. 129:107921. doi: 10.1016/j. ecolind.2021.107921

Gereffi, G. (1999). International trade and industrial upgrading in the apparel commodity chain. J. Int. Econ. 48, 37-70.

Gereffi, G., and Lee, J. (2016). Economic and social upgrading in global value chains and industrial clusters, why governance matters. J. Business Ethics 133, 25-38. doi: 10.1007/s10551-014-2373-7

Hackman, J. R. (1987). The Design of Work Teams. Hand Book Org. Behav. 35, 299-301. doi: 10.1016/0090-2616(78)90031-1

Hair, J. F., Hult, G. T. M., Ringle, C. M., Sarstedt, M., and Thiele, K. O. (2017). Mirror, mirror on the wall: a comparative evaluation of compositebased structural equation modeling methods. Acad. Mark. Sci. Rev. 45, 616-632. doi: 10.1007/s11747-017-0517-x

Hame, L. G. (1998). Strategy innovation and the quest for value. Sloan Manag. Rev. 39, 1-14.

Humphrey, J., and Schmitz, H. (2002). How does insertion in global value chains affect upgrading in industrial clusters? Reg. Stud. 36, 1017-1027. doi: $10.1080 / 0034340022000022198$

Humphrey, J., and Schmitz, H. (2004). "Chain governance and upgrading, taking stock, local enterprises in the global economy," in Issues of Governance and Upgrading. ed. H. Schmitz (United States: Edward Elgar Publishing).

Jaakko, A., Joe, L. H., and Henrikkl, T. (2010). Business model innovation vs replication, financial performance implications of strategic emphases. J. Strateg. Markt. 18, 39-56. doi: 10.1080/09652540903511290

Jackson, D. L., Gillaspy, J. A. Jr., and Purc-Stephenson, R. (2009). Reporting practices in confirmatory factor analysis, An overview and some recommendations. Psychol. Methods 14, 6-23. doi: 10.1037/a0014694

Jaworski, B. J., and Kohl, I. A. K. (1993). Market orientation, antecedents and consequences. J. Mark. 57, 53-70. doi: 10.1177/002224299305700304

Jefferson, G. H., Huamao, B., Guan, X. J., and Yu, X. Y. (2006). R\&D performance in Chinese industry. Econ. Innov. New Technol. 15, 345-366. doi: $10.1080 / 10438590500512851$

Jennings, Z. (1995). Ecologically sustainable organizations, an institutional approach. Acad. Manag. Rev. 20, 1015-1052. doi: 10.5465/amr.1995.9512280034

Jia, G., Zhang, G. Y., Yuan, X., Gu, X. S., Liu, H. S., Fan, Z. J., et al. (2021). A synthetical development approach for rehabilitation assistive smart productservice systems: a case study. Adv. Eng. Inform. 48:101310. doi: 10.1016/j. aei.2021.101310

Jia, X. X., and Zhao, N. M. (2014). An empirical study on the impact of inter-organizational network linkages on enterprise transformation and upgrading--an examination based on marine equipment manufacturing enterprises. Sci. Tech. Prog. Countermeasures 31, 87-93. doi: 10.6049/ kjjbydc. 2013120084

Kaplinsky, R., and Morris, M. (2003). A Handbook for Value Chain Research. Canada: International Development Research Centre.

Kline, R. B. (2005). Principles and Practice of Structural Equation Modeling. 2nd Edn. New York: Guilford Press.

Kline, R. B. (2011). Principles and Practice of Structural Equation Modeling. 3th Edn. New York, Guilford.

Kong, W. J. (2012). Research on the factors influencing the transformation and upgrading of manufacturing enterprises--an empirical study based on a large sample questionnaire survey of manufacturing enterprises in Zhejiang Province. Manage. World 9, 120-131. doi: 10.19744/j. cnki.11-1235/f.2012.09.012

Kong, Q. X., Li, R. R., Peng, D., and Wong, Z. (2021). High-Technology Development Zones and Innovation in Knowledge-Intensive Service Firms, Evidence from Chinese A-share listed firms. Int. Financial Anal. Rev. 78:101883. doi: $10.1016 /$ j.irfa.2021.101883

Korsgaard, M. A., and Roberson, L. (1995). Procedural justice in performance evaluation, The role of instrumental and non-instrumental voice in performance appraisal discussions. J. Manag. 21, 657-669. doi: 10.1177/014920639502100404

Leao, P., and da Silva, M. M. (2021). Impacts of digital transformation on firms' competitive advantages, A systematic literature review. Strateg. Change Brief. Ent. Finance 31, 421-441. doi: 10.1002/jsc.2459
Li, Y.,Li, L., Liu, Y., et al. (2005). Linking management control system with product development and process decisions to cope with environment complexity. Int. J. Prod. Res., 43,2577-2591, doi: 10.1080/00207540500045634.

Li, J. J., Poppo, L., and Zhou, K. Z. (2008). Do managerial ties in China always produce value? Competition, uncertainty and domesticvs. Foreign firms. Strateg. Manag. J. 29, 383-400. doi: 10.1002/smj.665

Li, Z., Shao, S., Shi, X. P., Sun, Y. P., and Zhang, X. L. (2019). Structural transformation of manufacturing, natural resource dependence, and carbon emissions reduction, evidence of a threshold effect from China. J. Clean. Prod. 206, 920-927. doi: 10.1016/j.jclepro.2018.09.241

Lin, M., Ren, H., and Dong, B. R. (2015). Structural binary balance of technological diversification, firm cohesiveness and exploratory innovation performance. Sci. Res. Manage. 36, 65-72. doi: 10.19571/j.cnki.1000-2995.2015.04.008

Luo, Y. D. (1997). Partner selection and venturing success, The case of joint ventures with firms in the People's republic of China. Organ. Sci. 8, 648-662. doi: $10.1287 /$ orsc.8.6.648

Luo, X. W., and Chi, N. C. (2005). Keeping it All in the family, The role of particularistic relationships in business group performance during institutional transition. Adm. Sci. Q. 50, 404-439. doi: 10.2189/asqu.2005.50.3.404

Ma, H. J., Dong, B. D., and Ge, B. S. (2014). Study on the relationship between entrepreneurial capability, dynamic capability and competitive advantage of firms. Sci. Res. 32, 431-440. doi: 10.3969/j.issn.1003-2053.2014.03.014

Makadok, R. (2001). Toward a synthesis of the resource-based and dynamic-capability views of rent creation. Strateg. Manage. 5, 387-401. doi: 10.1002/smj.158

Makadok, R., and Barney, J. B. (2001). Strategic factor market intelligence, An application of information economics to strategy formulation and competitor intelligence. Manag. Sci. 47, 1621-1638. doi: 10.1287/mnsc.47.12.1621.10245

Mang, P. Y. (1998). Exploiting innovation options, An empirical analysis of R\&D-intensive firms. J. Econ. Behav. Organ. 35, 229-242. doi: 10.1016/ S0167-2681(98)00055-9

Mao, Y. S., and Wang, J. C. (2006). Research on the path of independent innovation based on product upgrading. Manage. World 05, 114-120. doi: 10.19744/j.cnki.11-1235/f.2006.05.014

Mao, Y. S., and Wen, S. Y. (2012). A study of enterprise upgrading based on product function expansion. Aca. Res. 05, 75-82. doi: 10.3969/j. issn.1000-7326.2012.05.013

Mao, Y. S., Wu, Y., and Zou, H. X. (2010). A dynamic analytical framework and empirical study on the upgrading of OEM firms in China. Aca. Res. 01, 63-69.

McFarland, D. B., and Sweeny, P. D. (1992). Distributive and procedural justice as predictors of satisfaction with personal and organizational outcomes. Acad. Manag. J. 35, 626-637.

Mossholder, K. W., Bennett, N., Kemery, E. R., and Wesolowski, M. (1998). A. Relationships between bases of power and work reactions, The mediational role of procedural justice. J. Manag. 24, 533-552. doi: $10.1177 / 014920639802400404$

Murray, A. J., and Greenes, K. A. (2006). A research agenda for the enterprise of the future. Vine 36, 119-124. doi: 10.1108/03055720610682906

Nietoa, M., and Quevedo, P. (2005). Absorptive capacity, technologic opportunity, knowledge spillovers, and innovative. Technovation 25, 1141-1157. doi: 10.1016/j.technovation.2004.05.001

Podsakoff, P. M., MacKenzie, S. M., Lee, J., and Podsakoff, N. P. (2003). Common method variance in behavioral research. A critical review of the literature and recommended remedies. J. Appl. Psychol. 88, 879-903. doi: 10.1037/0021-9010.88.5.879

Podsakoff, P. M., and Organ, D. W. (1986). Self-reports in organizational research problems and prospects. J. Manag. 12, 531-544. doi: 10.1177/0149 20638601200408

Poon, S. C. (2004). Beyond the global production networks, a case of further upgrading of Taiwan's information technology industry. Int. J. Technol. Glob. 1, 130-144. doi: 10.1504/IJTG.2004.004555

Porter, M. E. (1991). Towards a dynamic theory of strategy. Strateg. Manag. J. 12, 95-117. doi: 10.1002/smj.4250121008

Pousette, A., and Hanse, J. J. (2002). Job characteristics as predictors ofill-health and sickness absenteeism in different occupational types, a multigroups tructural equation modelling approach. Work Stress 16, 229-250. doi: 10.1080/02678370210162737

Protogerou, A., Caloghirou, Y., and Lioukas, S. (2011). Dynamic capabilities and their indirect impact on firm performance. Ind. Corp. Chang. 8, 1-33. doi: $10.1093 /$ icc/dtr049 
Qiu, H. X., and Liu, S. Y. (2015). The impact of transformation and upgrading and corporate social networks on firm performance - an example of manufacturing firms in the Pearl River Delta region. J. South China Normal Uni. 4, 112-120.

Reis, C. F. D., de Souza, A. B., Araujo, E. C., and Blind, K. (2021). Value chains of the world's top manufacturing corporations, moving from tangible to intangible activities? J. Manuf. Technol. Manag. 32, 1312-1334. doi: 10.1108/ JMTM-08-2019-0306

Schaltegger, S., Ludeke-Freund, F., and Hansen, E. G. (2016). Business models for sustainability, A co-evolutionary analysis of sustainable entrepreneurship, innovation, and transformation. Organ. Environ. 29, 264-289. doi: $10.1177 / 1086026616633272$

Schumacker, R. E., and Lomax, R. G. (2010). A beginner's Guide to Structural Equation Modeling. 3rd Edn. United States: Taylor \& Francis Group.

Smith, S. M., Roster, C. A., Golden, L. L., and Albaum, G. S. (2016). A multigroup analysis of online survey respondent data quality, comparing a regular USA consumer panel to MTurk samples. J. Bus. Res. 69, 3139-3148. doi: 10.1016/j.jbusres.2015.12.002

Song, T. B., Chen, Y., Wu, X. J., and Wang, X. J. (2016). Research hotspots and research fronts of enterprise transformation and upgrading in chinabibliometric analysis based on CSSCI's data. Sci. Tech. Prog. Policy 33, 104-110. doi: 10.3969/j.issn.1000-7326.2015.01.009

Tang, Z., and Tang, J. (2012). Stakeholder firm power difference, stakeholders CSR orientation, and SMEs' environmental performance in China. J. Bus. Ventur. 27, 436-455. doi: 10.1016/j.jbusvent.2011.11.007

Verbeke, G., Fieuws, S., and Molenberghs, G. (2014). The analysis of multivariate longitudinal data: A review. Stat. Methods Med. Res. 23, 42-59. doi: 10.1177/0962280212445834

Vrolijk, K. (2021). Industrial policy and structural transformation, insights from Ethiopian manufacturing. Dev. Policy Rev. 39, 250-265. doi: 10.1111/dpr.12496

Wang, Q. (2007). An empirical analysis of the interaction between local technological innovation, foreign technological spillover and China's competitive advantage in manufacturing trade. Int. Trade Issues 11, 89-94.

Wang, Y. M. (2016). An empirical analysis of the influencing factors of green governance in the distribution industry chain--a case study of mountainous special agricultural products in the southwest ethnic region. China Circ. Eco. 30, 17-24. doi: 10.3969/j.issn.1007-8266.2016.07.002

Wang, J. M., Chen, H. X., and Yuan., (2010a). Mediating Role of Green Innovation Strategy of Firm Enterprises in Jiangsu. China J. Popul. Res. Environ. 20, 111-117. doi: 10.3969/j.issn.1672-0334.2010.01.007

Wang, N. X., Zhong, J. W., and Mei, S. E. (2010b). An empirical study of information technology, core competencies, and firm performance. Manag. Sci. 23, 52-64. doi: 10.3969/j.issn.1002-2104.2010.06.019

Wu, Y., Liang, Q. Z., and Wei, Z. L. (2013). A study on the impact of dual technological innovation and market orientation on firm performance, A disruptive innovation perspective. Sci. Tech. Manage. 34, 140-151.

$\mathrm{Xu}$, M. Z. (2015). Analysis of statistical applications of common method deviations. Camp. Manage. 27, 48-67.

Xu, J. Z., Jia, D. F., Li, F. S., and Wang, Y. (2018). A study on the impact of lowcarbon technology innovation on firm performance in equipment manufacturing firms. Manag. Rev. 30, 82-94. doi: 10.14120/j.cnki.cn11-5057/f.2018.03.008

$\mathrm{Xu}$, H., Lin, Z. G., and Rui, C. (2015). Product market competition, asset specialization, and horizontal mergers and acquisitions of listed companies. Nankai Manage. Rev. 18, 48-59. doi: 10.1080/07421222.1999.11518243
Yang, D. H., Zhang, Y. F., and Li, P. F. (2017). Supply-side structural reform and transformation of resource-based industries in China. China Popul. Res. Environ. 21, 18-24. doi: 10.12062/cpre.20170459

Yang, Y. L., Zhang, J., Sun, W. J., and Pu, Y. (2021). Research on NSGA-III in location-routing-inventory problem of pharmaceutical logistics intermodal network. J. Int. Fuzzy Sys. 41, 699-713. doi: 10.3233/JIFS-202508

Yuan, H. X., Feng, Y. D., Lee, C. C., and Cen, Y. (2020). How does manufacturing agglomeration affect green economic efficiency. Energy Econ. 92:104944. doi: 10.1016/j.eneco.2020.104944

Zhai, S. P., and Bi, K. X. (2016). Market pressure, financial subsidies and dual innovation investment in listed high-tech companies. Scientific decision making 6, 16-33. doi: 10.3773/j.issn.1006-4885.2016.06.016

Zhang, M. F., Dawson, J. F., and Kline, R. B. (2021). Evaluating the Use of CovarianceBased Structural Equation Modelling with Reflective Measurement in Organizational and Management Research: A Review and Recommendations for Best Practice. Br. J. Manag. 32, 257-272. doi: 10.1111/1467-8551.12415

Zhang, J. L., and Zhao, C. S. (2015). Industrial transformation and upgrading, performance, problems and countermeasures in China. Survey World 9, 3-7. doi: 10.13778/j.cnki.11-3705/c.2015.12.001

Zhao, Y. W., Luo, J. Q., and Feng, Q. H. (2020). An empirical research on the driving force of service innovation of manufacturing enterprises. Sci. Res. Manage. 41, 164-173. doi: 10.19571/j.cnki.1000-2995

Zhou, J. Y., and Yang., (2013). Dilemmas, Transformation Paths and Policy Needs of Guangdong Foreign Trade Enterprises - An Empirical Analysis Based on Structural Equations. International Economic and Trade Exploration 29, 4-15. doi: 10.13687/j.cnki.gjjmts.2013.04.010

Zhou, Y., Zhang, X. D., Zhao, Y., Chen, L. Y., and Xue, L. (2018). Industrial development and environmental performance under the regulation of green governance. China Popul. Res. Environ. 28, 82-92. doi: 10.12062/ cpre.20180402

Zhu, W. C. (2019). Study on the adjustment path of marine economic industrial structure in China's coastal provinces under the belt and road initiative. J. Coastal Stu. 98, 219-222. doi: 10.2112/SI98-054.1

Zhu, H. J., Chen, Q., and Jiang, M. B. (2006). Current situation and development countermeasures of OEM in China's home appliance industry. Bus. Res. 04, 96-98. doi: 10.3969/j.issn.1001-148X.2006.04.031

Conflict of Interest: The authors declare that the research was conducted in the absence of any commercial or financial relationships that could be construed as a potential conflict of interest.

Publisher's Note: All claims expressed in this article are solely those of the authors and do not necessarily represent those of their affiliated organizations, or those of the publisher, the editors and the reviewers. Any product that may be evaluated in this article, or claim that may be made by its manufacturer, is not guaranteed or endorsed by the publisher.

Copyright (c) 2022 Song, Hongsuchon, Kittikowit and Dong. This is an open-access article distributed under the terms of the Creative Commons Attribution License (CC BY). The use, distribution or reproduction in other forums is permitted, provided the original author(s) and the copyright owner(s) are credited and that the original publication in this journal is cited, in accordance with accepted academic practice. No use, distribution or reproduction is permitted which does not comply with these terms. 